The density (at $15^{\circ} .56 \mathrm{C}$.) of the sea-water which comes in contact with the lower surfaces of the icebergs is I.0255, which represents a chlorine percentage of $I^{\circ} 90$. Ice actually melting in this water would produce a temperature of $-\mathrm{I}^{\circ} .92 \mathrm{C}$. When ice is immersed in this water it lowers its temperature, and a portion of the ice is melted, producing dilution. The concentration, therefore, or chlorine percentage, which will determine the melting temperature of the ice, will be a little lower than that of the original sea-water. From the Challenger observations we see that, on the confines of the pack-ice the cold stratum of water has a uniform temperature of $29^{\circ} \mathrm{F} .\left(-\mathrm{I}^{\circ} 67 \mathrm{C}\right.$. $)$. Ice melts at this temperature in sea-water containing $I^{\circ} 65$ per cent. of chlorine. In this process ice is melted, so that roo grammes pure warm sea-water become I 9 grammes of diluted cold sea-water. It will be observed that the ice which has been formed in the atmosphere at a temperature of $32^{\circ} \mathrm{F}$. comes in this way to be melted at a temperature of $29^{\circ} \mathrm{F}$.; and the pressure exerted by the 300 fathoms of sea-water, though it may assist in the lowering of the melting temperature, is insufficient to account for the amount.

\section{TO FIND THE DAY OF THE WEEK FOR ANY GIVEN DATE}

HAVING hit upon the following method of mentally computing the day of the week for any given date I send it you in the hope that it may interest some of your readers. I am not a rapid computer myself, and as I find my average time for doing any such question is about 20 seconds, I have little doubt that a rapid computer would not need I 5 .

Take the given date in 4 portions, viz. the number of centuries, the number of years over, the month, the day of the month.

Compute the following 4 items, adding each, when found, to the total of the previous items. When an item or total exceeds 7 , divide by 7 , and keep the remainder only.

The Century-Item.-For Old Style (which ended September 2, 1752) subtract from 18. For New Style (which began September 14) divide by 4 , take overplus from 3, multiply remainder by 2 .

The Year-Item.-Add together the number of dozens, the overplus, and the number of 4's in the overplus.

The Month-Item.-If it begins or ends with a vowel, subtract the number, denoting its place in the year, from Io. This, plus its number of days, gives the item for the following month. The item for January is " 0 "; for February or March (the 3rd month), "3"; for December (the I2th month), "12."

The Day-Item is the day of the month.

The total, thus reached, must be corrected, by deducting "I" (first adding 7, if the total be "O"), if the date be January or February in a Leap Year : remembering that every year, divisible by 4 , is a Leap Year, excepting only the century-years, in New Style, when the number of centuries is not so divisible (e.g. 1800).

The final result gives the day of the week, "o" meaning Sunday, "I" Monday, and so on.

\section{EXAMPLES}

I783, September I8

I7, divided by 4 , leaves "I " over; I from 3 gives " 2 "; twice 2 is " 4 ."

83 is 6 dozen and $1 \mathrm{I}$, giving 17 ; plus 2 gives 19 , i.e. (dividing by 7) " 5 ." Total 9, i.e. " 2 ."

The item for August is "8 from Io," i.e. " 2 "; so, for September, it is " 2 plus 3," i.e. "5." Total 7, i.e. "o," which goes out.

I 8 gives "4." Answer, "Thursday."
1676, February 23

16 from 18 gives " 2. ."

76 is 6 dozen and 4 , giving Io ; plus I gives I , i.e. " 4 ." Total " $6 . "$

The item for February is " 3." Total 9, i.e. "2."

23 gives " 2. ." Total " 4 ."

Correction for Leap Year gives " 3." Answer, "Weinesday." LEwIS CARROLL

\section{NOTES}

IN the Report submitted yesterday at Edinburgh to the halfyearly general meeting of the Scottish Meteorological Society, the Council state that the work at the Ben Nevis Observatory continues to be carried on by $\mathrm{Mr}$. Omond and the assistants in the same highly satisfactory manner as has been recorded in previous Reports. In addition to the laborious work of observing at all hours of the day and night, of reducing the observations, and forwarding copies for the Societv and the Meteorological Council, the staff of the Observatory has given very effective assistance in the preparation of the tables of the meteorology of Ben Nevis now in the press. Several interesting researches are being conducted at the Observatory, the results of which will be communicated to a future meeting. The Directors took steps last autumn to raise subscriptions to clear off the debt on the institution, and to establish a low-level station at Fort William, at which hourly observations may be made for comparison 'with those at the Observatory. It is only by two sets of observations at the top and bottom of the mountain that the Ben Nevis Observatory can be utilised, with the desired success, in the furtherance of meteorological science, but particularly in that branch of it which concerns the improvement of the system of forecasting the weather of the British Islands.

ON Tuesday evening last the Lord Advocate stated in the House of Commons that the Scottish Universities Bill would shortly be introduced.

The Paris Medical Faculty has decided to alter considerably the mode of competition for its Fellowships. The general object of the changes is to secure more original workers. The thesis (which has usually been the work, not of the candidate himself, but of his friends) is to be suppressed. Each candidate will henceforth have to deliver a lecture on his own scientific researches.

THE French Chamber of Deputies has decided that the buildings of the College of France shall be considerably enlarged. Fifty years ago, when this institution had only seventeen pro. fessors, its present buildings were sufficient; but now, when it has forty-one professors, they are very inadequate. It is to have four new lecture-rooms, a geological gallery, a set of rooms for other collections, a library, a meeting-room for professors, and eight laboratories. These additions will cost over 9,000,nno francs.

THE Anatomical Society, founded last September at Berlin, will hold its first general meeting at Leipzig on April 14. The Society has now over 170 members in England, Germany, Austria, Hungary, Switzerland, Holland, Belgium, Scandinavia, France, Russia, Italy, and North America.

DR. Hans ReuCH, who has lately devoted much time to the study of earthquakes in Norway, has issued a tabulated circular, which has been reproduced in the entire Norwegian Press, requesting that reports of any phenomena observed in connexion with earthquakes may be sent to him. By Government permission all such reports may be transmitted through the post free of charge. Dr. Reuch asks especially for information 